\title{
Experimental Study on Compression-bending of A New Type Wall Panel
}

\author{
Yan Liu', a, Yunxiang Fu' ${ }^{1, b}$, Xiaolai $\mathrm{Yu}^{1, \mathrm{c}}$ and Rongxin Tian ${ }^{1, \mathrm{~d}}$ \\ ${ }^{1}$ Yangzhou University, Yangzhou, 225009, China \\ aliuyan@yzu.edu.cn, b1295419120@qq.com, calfbi007@qq.com, d1030762023@qq.com
}

\begin{abstract}
Keywords: EVG-3D, axial compressing, compression-bending, failure mode, calculation formula Abstract. With the adjustment of China's industrial policy, clay bricks which were used for many years has been out of the building field, and some new wall body materials are developing as the main current gradually, including a new wall called EVG-3D introduced from EVG Company in Austria. In this paper, three new EVG-3D wall panels were tested at the action of axial compressing and compressing-bending respectively, and the mechanical characteristics of combined action of two plates of concrete and the steel wires with concrete of EVG-3D specimen were analyzed. Based on the test results of axial compressing, compression-bending of EVG-3D wall panels, calculation formula for the axial compressing, and compression-bending capacity were researched simultaneously. These results obtained serve as a basis for compiling engineering regulations of this new composite wall material.
\end{abstract}

\section{Introduction}

The clay brick applied for many years has stepped down from the building field since 2010 in China, and some new wall body materials are developing as the main current gradually, including a new wall body material EVG introduced from EVG-3D[1] company in Austria. Characteristics of the new wall are that both sides are units composed of cold-drawn steel wire and concrete layer and the middle is polystyrene insulation core body, which is fixed using horizontal steel wire to connect concrete layers. There is great difference between pouring \& plastering mode of wall piece and connection mode of wall body and floor beam in Austria and the United States, and that in China. Although such two countries conduct static test for a large number of wallboards, it also shows that bearing capacity of wallboard is related to pouring \& plastering construction mode of concrete at both edges of wall piece, connection mode of wall body, and floor beam etc. Therefore, to further understand the load bearing feature of wall piece and combined action of two concrete layers, axial compression and bending tests are conducted for EVG-3D wallboard at shaking table laboratory of state key laboratory of disaster prevention for civil engineering of Tongji University. Boundary dimension of test specimen is $1200 \times 2400 \mathrm{~mm}$ and concrete size and structure of test wallboard are shown in Figure 1.

\section{Test Program of EVG-3D Wallboard}

\section{Test loading proposal}

Static loading scheme is adopted for the test [2, 3, 4]. For compression-bending test, conduct vertical loading firstly and then horizontal loading. Loading arrangement and scheme of the test are shown in Figure 2

\section{Test measurement scheme}

The strain measurement points for axial compression and compressing-bending tests are arranged as follows.

Strains of connecting reinforcement for wallboard and loading beam, that of wallboard and floor beam and of vertical reinforcement for wallboard as well as vertical strain of concrete surface are measured through 2 strain gauges; vertical displacement of wall top relative to floor beam is read from 
2 displacement meters; the pressure is measured with and read from Schenk tester at axial compression test.

Strains of constructional reinforcement (both sides of wallboard) for wallboard and loading beam, that of wallboard and floor beam and of vertical steel wire bottom (both sides of wallboard) for wallboard are measured through 4 strain gauges; strains of compression end for concrete and horizontal steel wire for wallboard are measured through 2 strain gauges; displacements at wall top side and floor beam side and vertical displacement of wall top relative to floor beam are read from 2 displacement meters; observe the load and development when crack occurs; the pressure is measured with and read from piezometer and Schenk tester at compressing-bending test.

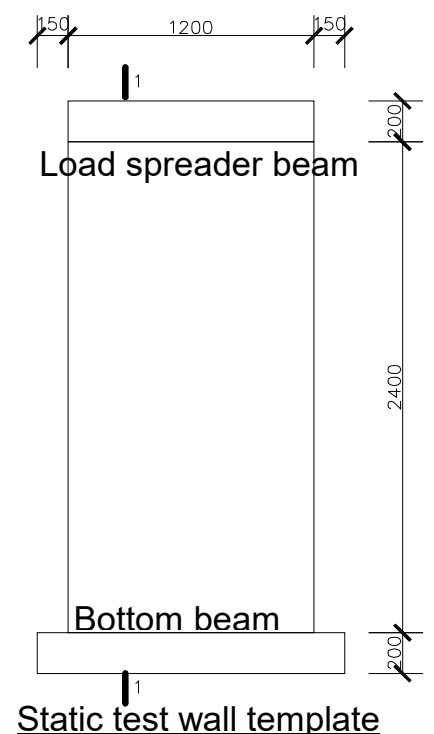

Figure 1. The structural arrangement of the test wall panels

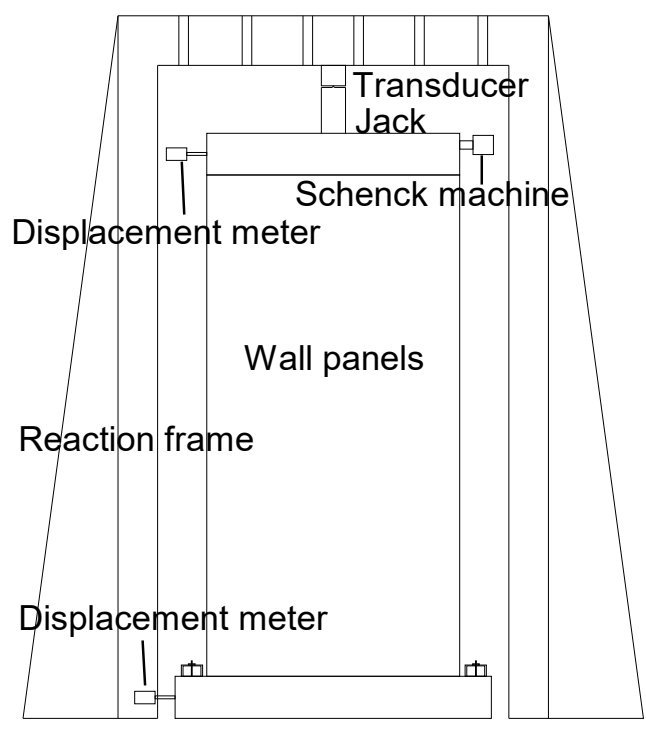

Figure 2. The layout of the test wall panels

\section{Test Data}

Wall body displacement and strain values at different measurement points during axial compression and bending tests (vertical loading first and horizontal loading last) are measured and recorded.

\section{Phenomena of Axial Compression and Bending Tests for EVG-3D Wallboard Unit}

Phenomena of axial compression test for EVG-3D wallboard unit are as follows. At initial crack stage, when vertical pressure is $433.5 \mathrm{kN}$, concrete layer at bottom of wall unit corner cracks, maximum vertical strains of vertical steel wire and vertical connecting reinforcement are $241 \mu \varepsilon$ and $290 \mu \varepsilon$ respectively and average vertical compressive strain is $223 \mu \varepsilon$. Along with aggravated damage to end concrete loaded, local concrete bulges outward and strain growth of vertical steel wire and vertical connecting reinforcement is very slow. Under action of $750 \mathrm{kN}$ vertical load, at approximate horizontal section on top of joint bar, concrete breaks outside the plane, vertical steel wire yields, joint bar leans outward, which has great influence on overall stability of wall piece, and average vertical compressive strain is $610.5 \mu \varepsilon$ with small change, of which the reason may be instability out of plane. Figure 3 shows the relation between axial pressure and average compressive strain of concrete and Figure 4 shows the failure state of the wall specimen under axial compression test.

Phenomena of bending (vertical loading is made firstly) test for EVG-3D wallboard unit are as follows. Compressive stress of concrete borne on overall section is uneven, and when axial pressure is $450 \mathrm{kN}$, the concrete at bottom end cracks and maximum compressive strain measured is $3059 \mu \varepsilon$. Strains of vertical steel wire (both ends) are small relatively and maximum compressive strain measured is $1897 \mu \varepsilon$. Strain growth of vertical connecting reinforcement after axial pressure reaches $360 \mathrm{kN}$ is far less than that of concrete and maximum compressive strain measured is $1022 \mu \varepsilon$; Strains 
of horizontal steel wires are small and do not exceed $150 \mu \varepsilon$ at most. Figure 5 shows the relation between axial pressure at different levels and strain value.

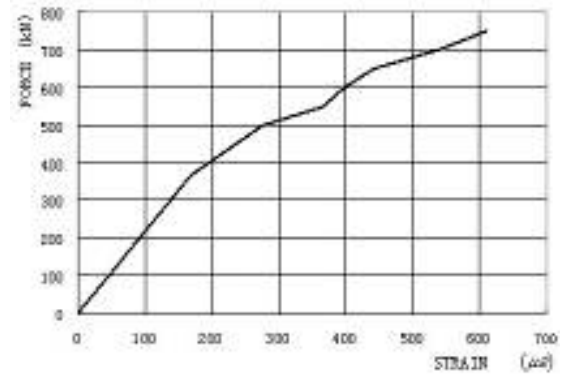

Figure 3. Relationship of axial force andaverage strain of concrete in axial compression test

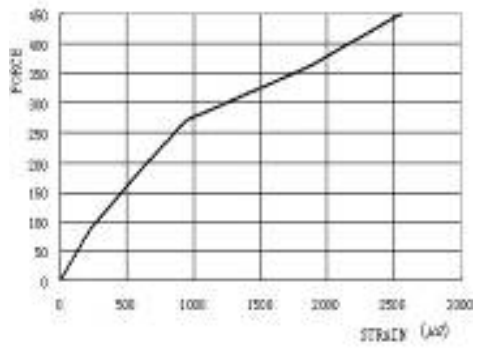

Figure 5. Relationship of axial force and average strain of concrete in compression-bending test(Vertical loading first)

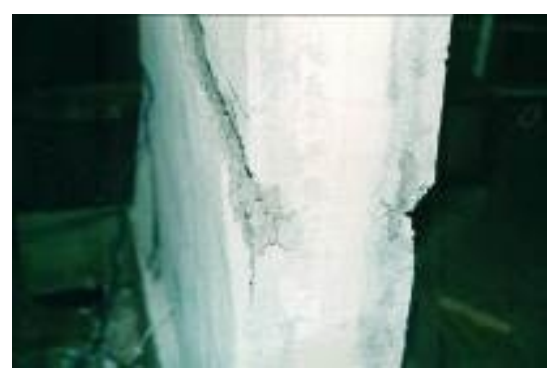

Figure 4. Failure mode of axial compression test

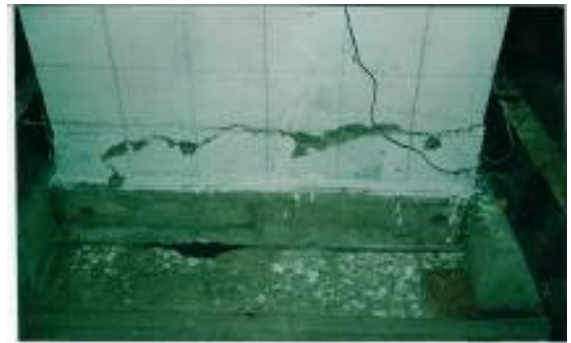

Figure 6. Failure mode of compression-bending test

Comparing phenomena of bending (vertical loading is made firstly) test for EVG-3D wallboard unit with that of axial compression test shows that the initial crack loads are close relatively, but there is great difference between strain values measured. The main reason is that measurement points of bending test are arranged at both edges of wall piece, while that of axial compression test are arranged in middle of wall body and eccentricity within wall body plane bears pressure.

Phenomena of bending (horizontal loading is made lastly) test for EVG-3D wallboard unit: compressed damage area of concrete increases obviously, the damage is brittle and diagonal crack has no further development. Maximum compressive strain measured has recovered $5000 \mu \varepsilon$. When the pressure is $40 \mathrm{kN}$, steel wire at end buckles, concrete bulges outward, maximum horizontal bearing capacity is $60 \mathrm{kN}$ and maximum compressive strain measured is $1200 \mu \varepsilon$. Strain of vertical connecting reinforcement at tension end or compression end is within $2000 \mu \varepsilon$. Strain values of horizontal steel wire are small and maximum value measured is $260 \mu \varepsilon$. Figure 6 shows the damage status of wall piece during bending test.

\section{Analysis of Bearing Capacity of Wall Piece Unit}

Numerous test analyses and theoretical analyses show that it is difficult to separate the shearing action from bending action of low reinforced concrete wall body and simplification of separation from bending action to shearing action for medium-high wall may be made. The specification gives simplified bearing capacity formulas of ordinary concrete wall body[5]. Seen from test data and phenomena, steel wire concrete layers at both edges have good combined action performance and the reinforcement and concrete layer at elastic and elastic-plastic stages have good cooperativity. Therefore, analysis of static bearing capacity of EVG-3D wallboard may be made by referring to these formulas.

\section{Calculation of axial compression bearing capacity for wall piece unit}

Simplify the wall piece as rod piece. The regional theories applied most widely for inelastic bending region of axis pole are: double modulus theory, tangent modulus theory and Shanley's theory, 
of which the nature is based on Euler column analysis. Among them, the theory applied most widely is tangent modulus theory:

$\sigma_{1}=N_{1} / A ; N_{i}=\pi^{2} E_{t} I / l^{2}$.

Wherein: Et_-tangent modulus

For EVG-3D axial compression wallboard, to make the compressive bearing capacity of right section is consistent with that of reinforced concrete structure in China; it may be calculated according to the bearing capacity calculation formula of axial compression member given below in the specification:

$$
N \leq \varphi\left(f_{\mathrm{c}} A+f_{\mathrm{y}}^{\prime} A_{\mathrm{s}}^{\prime}\right) .
$$

Concrete meaning is shown in GB 50010-2010, Article 7.3.1[2].

Calculation of cross-section bearing capacity of Evg-3D compression wallboard with large eccentricity

Assuming that the contribution of steel wire (reinforcement) at compression and tension of steel wire (reinforcement) nearby neutral axis are ignored and only yield strength of tension steel wire (reinforcement) with length less than $h_{\mathrm{w} 0}-1.5 x$ is considered; therefore, the approximate formula below is derived for EVG-3D wallboard with large eccentricity:

$$
\begin{aligned}
& N=\alpha_{1} f_{\mathrm{c}} b_{\mathrm{w}} x-\left(h_{\mathrm{w} 0}-1.5 x\right) \frac{A_{\mathrm{sw}}}{h_{\mathrm{w} 0}} f_{\mathrm{yw}}+f_{\mathrm{y}}^{\prime} A_{\mathrm{s}}^{\prime}-f_{\mathrm{y}} A_{\mathrm{s}} \\
& M=\alpha_{1} f_{\mathrm{c}} b_{\mathrm{w}} x\left(h_{\mathrm{w} 0}-\frac{x}{2}\right)-\frac{A_{\mathrm{sw}} f_{\mathrm{sw}}}{2 h_{\mathrm{w} 0}}\left(h_{\mathrm{w} 0}-1.5 x\right)^{2}+f_{\mathrm{y}}^{\prime} A_{\mathrm{s}}^{\prime}\left(\frac{h}{2}-a_{\mathrm{s}}^{\prime}\right)
\end{aligned}
$$

The stress graph of wall-column section under ultimate limit state of bearing capacity is shown in Figure 7.

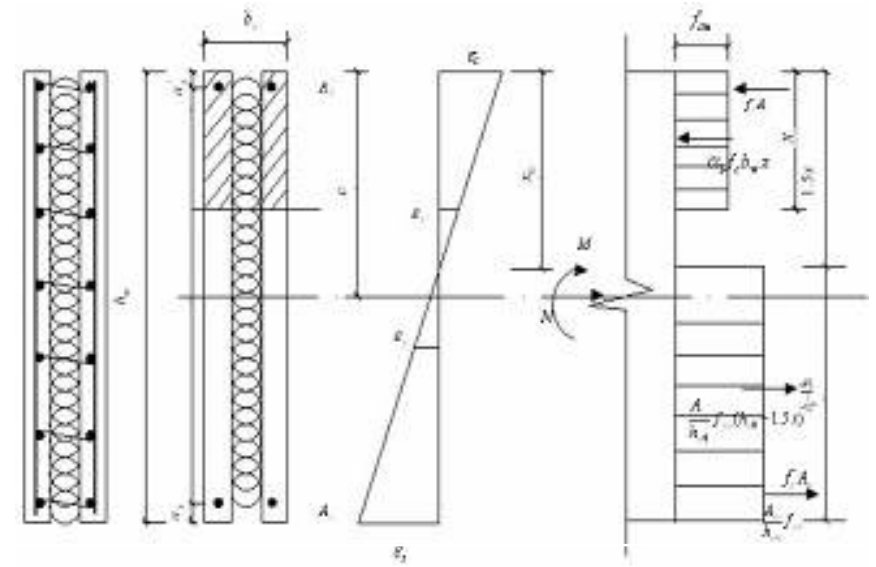

Figure 7. Strain and stress distribution of large-eccentric compression section of wall

Wherein:

$\mathrm{N}$ is design value of axial force for wall column; $f_{\mathrm{y}}, f_{\mathrm{y}}^{\prime}$ and $f_{\mathrm{yw}}$ are design values of vertical tension and compression reinforcements at the end of wall and strength for reinforcement distributed vertically within the wall body respectively; $f_{\mathrm{c}}$ is design value of compressive strength for concrete bending; $A_{\mathrm{s}}$ and $A_{\mathrm{s}}^{\prime}$ are sectional areas of tension and compression reinforcements at end of wall; $h_{\mathrm{w}}$ is section height of wall; $h_{\mathrm{w} 0}$ is calculated section height of wall, i.e. $h_{\mathrm{w}}=h_{\mathrm{w}}-a_{\mathrm{s}} ; b_{\mathrm{w}}$ is section thickness of wall.

For $\alpha_{1}$ coefficient, when concrete strength is not more than grade $\mathrm{C}, \alpha_{1}=1.0$; when concrete strength is grade $\mathrm{C}, \alpha_{1}=2.0$; when concrete strength is between grade 5 and $8, \alpha_{1}$ is taken according to linear interpolation.

Calculation of cross-section bearing capacity of EVG-3D compression wallboard with small eccentricity

For EVG-3D wallboard with small eccentricity, it is assumed that tension steel wire at end of wall does not yield and contribution of compressive yield steel wire (reinforcement) is ignored and it is 
believed that the steel wire (reinforcement) has buckled at this time. Assume according to plane section and calculate with the approximate formula below:

$$
\begin{aligned}
& N \leq \alpha_{1} f_{\mathrm{c}} \xi b_{\mathrm{w}} h_{\mathrm{w} 0}+f_{\mathrm{y}} A_{\mathrm{s}}^{\prime}-\sigma_{\mathrm{s}} A_{\mathrm{s}} \\
& M \leq \alpha_{1} f_{\mathrm{c}} \xi(1-0.5 \xi) b h_{\mathrm{w} 0}^{2}+M_{\mathrm{sw}}+f_{\mathrm{y}}^{\prime} A_{\mathrm{s}}^{\prime}\left(h_{\mathrm{w} 0}-a_{\mathrm{s}}^{\prime}\right)
\end{aligned}
$$

Wherein:

$$
\begin{aligned}
& M_{\mathrm{sw}}=\left[0.5-\left(\frac{\xi-0.8}{0.8 \omega}\right)^{2}\right] f_{\mathrm{yw}} A_{\mathrm{sw}} h_{\mathrm{sw}}-\xi(1-\beta) A_{\mathrm{sw}} f_{\mathrm{yw}} \frac{(2-\xi+\xi \beta) h}{2} ; \\
& N_{\mathrm{sw}}=\left(1+\frac{\xi-0.8}{0.4 \omega}\right) f_{\mathrm{yw}} A_{\mathrm{sw}}-\xi(1-\beta) A_{\mathrm{sw}} f_{\mathrm{yw}} ; \beta=f_{\mathrm{yw}} / 0.003 E_{\mathrm{s}} ; A_{\mathrm{sw}}=d h_{\mathrm{sw}}=\omega d h_{\mathrm{w} 0} .
\end{aligned}
$$

\section{Shear bearing capacity of oblique section for bending wallboard}

According to the formula given in the specification:

$$
V \leq \frac{1}{\lambda-0.5}\left(0.5 f_{\mathrm{t}} b_{\mathrm{w}} h_{\mathrm{w} 0}+0.13 N \frac{A_{\mathrm{w}}}{A}\right)+f_{\mathrm{yv}} \frac{A_{\mathrm{sh}}}{s} h_{\mathrm{w} 0}
$$

Wherein: For horizontal axial force, if; $N \geq 0.2 f_{\mathrm{c}} b_{\mathrm{w}} h_{\mathrm{w}}, N=0.2 f_{\mathrm{c}} b_{\mathrm{w}} h_{\mathrm{w}}$;

$\lambda$ is shear span ratio calculated at section, $\lambda=M / V h_{\mathrm{w} 0}$; when $\lambda<1, \lambda=1$; when $\lambda>2, \lambda=2$; When the distance between section and wall bottom calculated is less than $h_{\mathrm{w} 0}, \lambda$ should be calculated according to the bending moment and shearing force at $h_{\mathrm{w} 0}$ to wall bottom.

\section{Comparison of Theoretical Calculation Value and Actually-measured Value}

\section{Actually-measured strength of wall body material}

Through material test of wall body, compressive strength of fine aggregate concrete for wall surface, strengths of connecting reinforcement and steel wire for wall piece are obtained in [5].

\section{Bearing capacity of wall piece}

Comparison of axial compression bearing capacity for wall piece

According to $\lambda=\sqrt{A(k l)^{2} / I}=69$, axial compression bearing capacity may be obtained based on the formula given in the specification and by looking up corresponding value in the table, as shown in Table 1 in details.

Table 1 Calculation of axial bearing capacity of wall

\begin{tabular}{ccccc}
\hline Axial bearing capacity & $N_{\mathrm{p}}[\mathrm{kN}]$ & $N_{\mathrm{c}}[\mathrm{kN}]$ & $N_{\mathrm{k}}[\mathrm{kN}]$ & $N_{D}[\mathrm{kN}]$ \\
\hline Ultimate load & 779 & 750 & 780 & 563 \\
\hline
\end{tabular}

Wherein: $N_{k}$ is axial compression bearing capacity of wall body obtained through calculation according to standard strength of wall body material given in the specification; $N_{p}$ is axial compression bearing capacity of wall body obtained through calculation according to actually-measured material strength of wall body unit; $N_{c}$ is axial compression bearing capacity of wall body for actually-measured wall body unit; $N_{D}$ is axial compression bearing capacity of wall body through calculation according to design strength of wall body material given in the specification.

Comparison of bending and compression capacity for wall piece

Bending of wall piece is calculated according to formula (3) with calculation results being shown in Table 2.

Table 2 Calculation of bearing capacity of compression-bending

\begin{tabular}{ccccc}
\hline Bending capacity & $R_{\mathrm{p}}[\mathrm{kN}]$ & $R_{\mathrm{c}}[\mathrm{kN}]$ & $R_{\mathrm{k}}[\mathrm{kN}]$ & $R_{D}[\mathrm{kN}]$ \\
\hline Ultimate load & 173.2 & 60 & 157.2 & 139.6 \\
\hline
\end{tabular}

Wherein: $R_{\mathrm{k}}$ is bending bearing capacity of wall body obtained through calculation according to standard strength of wall body material given in the specification; $R_{\mathrm{p}}$ is bending bearing capacity of wall body obtained through calculation according to actually-measured material strength of wall body 
unit; $R_{\mathrm{c}}$ is bending bearing capacity of actually-measured wall body unit; $R_{D}$ is bending bearing capacity of wall body obtained through calculation according to design strength of wall body material given in the specification

\section{Conclusion}

The paper analyzes the static characteristics of EVG-3D wallboard unit briefly by combining analysis of axial compression and bending tests of three wallboard units. Due to condition restrictions, number of wall pieces made is limited. Characteristics of wall piece for the test are summarized as below:

Since EVG-3D wallboard belongs to reinforced concrete structure (component) in nature, the analysis method may be adopted, which is same with that of reinforced concrete structure (component).

Working performance evaluation of wallboard: two layers of concrete has good synergistic effect; strain of steel wire and concrete have good coordination at elastic and elastic-plastic stages.

Fine aggregate concrete is adopted as concrete layer of wall piece. Due to that artificial skin separating and smearing are adopted, the compressive strength of concrete should be reduced as $60 \%$ theoretically. Therefore, machine smearing is suggested for concrete during site construction.

Wall piece under axial compression effect may have buckling failure out of plane easily. In addition, there is large eccentricity within the plane and the concrete at end within the plane may be crushed easily at first. When axial compression bearing capacity is calculated according to the formula in the specification, it is suggested that the anti-bending inertia moment adopted be reduced appropriately, for which the coefficient may be $2 / 3$.

Since local concrete damage may be caused easily for wall piece by the eccentric in the plane under the axial compression, structural measures should be made in the opening of the bearing wall..

\section{Acknowledgments}

The authors would like to express sincere thanks to Jiangsu provincial Science and Technology Department of China. This research was funded from Policy Guidance Plan (Industry-University Research Cooperation) of Science and Technology Department of Jiangsu Province in 2016. (Grant No. BY2016069-04).

\section{References}

[1] Ming Xu and Fang Xu. Feature of 3D Light Wall Panels and Production Line from EVG Company in Austria. China Building Science. 2002. pp:121-123

[2] Bingbing Li, Jianxi Li, Sigong Chen and Yunfeng Li. Experimental Study on Lightweight Mural Material with Phosphogypsum. Bulletin of the Chinese Ceramic Society. 2012(2):362-376

[3] Fawei Qiu and Peng Pan. Quasi-static Loading and Control for Structural Test. China Civil Engineering Journal. 2002(1):1-5

[4] Yan Liu, Weixing Shi, Jun Hao, Huanzhou Wu and Xiangyu Su. 2015. "Test Study of Bending and Compressing-Bending of EVG -3D Wall Panels". Industrial Construction. 2015(10):96-100

[5] Lieping Ye. Concrete Structure (Volume One). China Architecture \& Building Press.2013. 